\title{
DIRECT PERMANENT RESTORATIVES - AMALGAM VS COMPOSITE
}

Bhagyashree Patki ${ }^{1}$

\section{HOW TO CITE THIS ARTICLE:}

Bhagyashree Patki. "Direct permanent restoratives - amalgam vs composite". Journal of Evolution of Medical and Dental Sciences 2013; Vol. 2, Issue 46, November 18; Page: 8912-8918.

ABSTRACT: Dental restoration is the most commonly administered dental treatment. These restorations are subjected to dynamic conditions in oral cavity, are likely to fail and need replacement. Ideal restorative material should pass two tests- Longitivity and Esthetics. Longitivity of the restorative material depends on three major factors- first is Patient's factors, second is Operator`s skills and last is the Restorative material itself. Dentists today have a plethora of materials to choose from. Materials like Silver Amalgam being tested over a century, other nubile but promising materials, developed recently and yet to be tested in long run. This puts a dentist in dilemma so as which material to select to ensure durable clinical performance after placement. Amalgam has been tested over 165 years and has fulfilled almost all desired qualities of a restorative material except esthetics. On the other hand composites have advantage in cases where esthetics is of prime importance; however Recent studies conclude them at par with amalgam ${ }^{1}$. Performance of these two materials is assessed on following criterions - Longevity, wear resistance, cost effectiveness, marginal leakage and predisposal to secondary decay, biocompatibility, pulp irritation, tooth preparation, technique sensitivity and esthetics.

KEY WORDS: Restorative materials, Dental Amalgam, Composite resins.

INTRODUCTION: Oral and dental diseases are one of the most prevalent chronic diseases. Dental decay alone affects around 5 billion people worldwide. Treatment is expensive and around $90 \%$ cases remain untreated in developing countries ${ }^{2}$. Majority of the dental and oral diseases arise from untreated dental caries. Restoration of the decayed lesion is one of the remedies and has been attempted since centuries. These restorations are subjected to dynamic conditions in oral cavity they are likely to fail, thus need timely replacement. Numerous attempts are being made all over the world to develop more durable and esthetically acceptable materials. Purpose of this review article is to compare and help a clinician to select the right restorative material from Amalgam and Composite resin; the two most commonly used direct restorative materials worldwide.

\section{REVIEW OF LITERATURE:}

Longevity: Longevity is a major deciding factor while selecting restorative material. Restorations have limited life span and likely to be replaced at some point of time. The studies on amalgam show good rates of survival compared with most of the other materials. At 3 years, no study showed failure and at 10 years, less than $10 \%$ of restorations had been replaced over period of time ${ }^{3}$. Evidence suggests that dispersed phase; high copper alloy amalgams are associated with greater survival than other amalgams-10. However composites are more often replaced than amalgam ${ }^{3,10-13}$. Composites demonstrate good short term Survival around 2 and 3 years if used without dentine bonding agent 14-18. Significant failure rate is associated with fillings over 5 years ${ }^{11,12}$. Survival of composite was influenced significantly by type of material. Light cured microfilled and densified filled materials being more successful between 6.5 years and 8.5 years, whereas the older 
autopolymerising macrofilled composites were most successful up to 6.5 years ${ }^{3}$. According to another study considering longitivity of posteriors restorations, Amalgam shows excellent longevity data with studies up to 20 years. The average annual failure rate is 0.3-6.9\%. Posterior composites are in the same range (0.5-6.6\%); however, the study times are much shorter (max. 10 years).Dental amalgam is easy to place in the prepared tooth, has low creep, high compressive strength, high resistance to wear and experiences minimal dimensional change with time ${ }^{19,20}$. Yet another study shows the mean annual failure rate was $2.9 \%$ for resin-composite restorations and $1.6 \%$ for amalgams. For resin-composite restorations, secondary caries being most frequent reason for replacement $(73.9 \%)$, some were lost $(8.0 \%)$, few fractured $(5.3 \%)$, and smaller quantity showed marginal defects $(2.4 \%)^{21}$. Tough composite is the most commonly used alternative to amalgam, but moderate to large composite restorations have higher failure rates, more secondary decay and increased frequency of replacement as compared to amalgam ${ }^{22,23}$. According to a comparative study of amalgam and composite restorations done in Norway, the mean age of failed amalgam restorations is around 11 years while the mean age for failed composite restorations is around 8 years; significantly lower than amalgam ${ }^{10}$. Other study shows hybrid and microfilled composites that were placed after the enamel-etching technique and proper isolation (rubber-dam) showed the good overall performance; the longevity of these restorations was similar to amalgam restorations. However, Compomer restorations, macrofilled composites, and resin restorations without etching or self-etching adhesives demonstrated significant failure rate ${ }^{1}$.

Wear resistance: Wear resistance refers to the material's ability to resist surface loss as a result of abrasion with other structures. Position of the tooth and occlusion are key factors in assessing wear resistance. Composite shows lower wear resistance than amalgam and not the material of choice for patients with heavy occlusion, bruxism and large occlusal coverage ${ }^{24,25}$. whereas some studies indicate that contemporary composites show wear resistance similar to amalgam ${ }^{26,27}$. Composite while yet not as wear resistant as amalgam, the difference is becoming lesser and lesser.

Cost Effectiveness: Amalgam clearly overcomes composites when it comes to cost effectiveness. Composite was between 1.7 and 3.5 times more expensive than amalgam ${ }^{3}$. Composite takes approximately 2.5 times longer time for placement, because complex incremental techniques are needed making it less revenue generating for the dentist ${ }^{13}$.

Marginal leakage and predisposal to secondary decay: Marginal leakage is the penetration of fluids, bacteria and ions into the space existing between restorative material and cavity walls. It is a measurement of how well a restoration adapts to a prepared tooth. Low creep and high tensile strength give amalgam an upper hand. It is the only dental material known for marginal-sealing capacity due to the corrosion products released from dental amalgam restorations ${ }^{19,22,28 .}$. This results in superior clinical performance and predisposes teeth to secondary caries to almost negligible extent. It also tolerates a wide range of clinical placement conditions such as wet field (zinc-free products). Amalgam does not show any significant dimensional change except when it is contaminated during trituration ${ }^{29}$.

On the other hand a phenomenon called polymerization shrinkage, which is basically the volumetric shrinkage; hampers long-term clinical success of composite resins. When margins extend 
onto root surface or dentine polymerization shrinkage causes a pulling away of material resulting in $\mathrm{V}$ shaped gap between composite and hybridized dentine. Contemporary composite materials shrink during polymerization, resulting in a volumetric reduction ranging from 1.5 to $5 \%$ depending on the molecular structure of the monomer, the amount of filler, and the rate of cure ${ }^{30}$. Polymerization shrinkage is undesirable for good clinical performance because it stresses tooth-composite bond interfaces and deforms the tooth ${ }^{31,32}$. These stresses may cause microfractures in the enamel, marginal $\mathrm{V}$ gap formation and subsequent microleakage or pain $33,34,35$. Higher the shrinkage greater the chances of bond disruption and this leads to leakage around margins and secondary caries. Low shrinkage polymers and incremental placement, use of a liner or soft start polymerization instead of high intensity light curing reduce marginal leakage to certain extent. Using microfilled composite with lower modulus of elasticity thus making it more flexible gives good results in Class $\mathrm{V}$ cavities where esthetics is concerned ${ }^{25}$. In general excellent results cannot be guaranteed when using resinbased composites for posterior restorations e.g. Class I cavity with $\mathrm{C}$ factor of 5 . A study says multisurface restorations done with composites show higher failure rate as compared to amalgam due to polymerization shrinkage which can still be regarded as the primary negative characteristic of composite resins ${ }^{36,37}$. Hodge found that the overall failure rate of the composite restorations in posterior teeth at eight years was $13.7 \%$ for composite. The failure rate of the composite restorations was approximately two to three times that of the control; high copper amalgam restorations (5.8\%). Loss or fracture and secondary decay at the margins were main reasons for failure, comprising $72 \%$ of the known modes of failures 26 .

Biocompatibility: Dental Amalgam still faces much dreaded controversy regarding mercury toxicity. The Council of Scientific Affairs of the American Dental Association (ADA) concluded in 1998 that amalgam can be safely used in adults and children and effective restorative material in view of scientific information available in past and present ${ }^{38}$. ADA again affirmed this statement in 2002, 2003, and 2009. Available evidences do not directly relate amalgam to mercury toxicity, nor do they justify discontinuation of amalgam, except certain contraindications like esthetics and pregnancy. Allergic reactions though observed but are extremely rare 22,39 .

Pulp Irritation: Amalgam is a non-insulating material that needs deeper tooth preparation; has potential cause thermal insult to pulp in deep cavities. A varnish, liner or base can prevent the damage. Chemically cured composite resins if not properly lined have potential to evoke moderate to severe pulp response but UV light cured or Visible light cured materials are relatively safe and can be used in deep cavities as well 22,39 .

Tooth preparation: Conservative cavity preparations retain the restorations better, leaving stronger remaining unprepared tooth structure for support .Also, smaller size of restorations ensures lesser damage to pulp. Amalgam restorations are mechanically locked in the tooth, as it does not bond to the tooth. Cavity preparation needs adequate depth, width, flat floor and inverted walls in order to retain amalgam. Sometimes retention grooves, locks, pins, slots and dovetails are necessary for retention ${ }^{25}$. These specifications result in aggressive removal of tooth structure and weaken the remaining tooth. Bonded and resin coated amalgams are some alternatives offering good initial marginal seal but technique sensitivity increases 25 .On the other hand, Composite micro- 
mechanically bonds to the tooth and restorations do not typically require tooth preparations as precise as amalgam and inlay castings. Conservative removal of tooth structure supports the restoration better ${ }^{6}$. However for replacement the new cavity after removal is more conservative in amalgam restoration as cavity margins and restoration can be differentiated clearly ${ }^{4}$.

Technique sensitivity: Technique of insertion plays a major role in order to restore the tooth to its original function. Composite restorations are retained much longer if they bond harmoniously to the enamel and dentine. Bonding to tooth structure requires good isolation (rubber dam application) from contamination by oral fluids and other contaminants ${ }^{25}$. Therefore ability to isolate plays major role in case selection for composites. Amalgam (Non bonded) and does not show any significant clinical problems even in presence of some oral fluids. Zinc free alloys show minimal expansion even placed in wet fields ${ }^{25,29}$.

\section{SUMMARY:}

Advantages of Amalgam: Ease of use, low technique sensitivity, and lower cost as compared to composite makes Amalgam popular among patients and dentists. Amalgam demonstrates favorable long-term clinical results as it has high tensile strength, excellent wear resistance and unique marginal sealing effect by corrosion products.

Disadvantages of amalgam: Amalgam is a non-insulating material that needs deeper tooth preparation; has potential cause thermal insult to pulp in deep cavities. A varnish, liner or base can prevent the damage. Extensive tooth preparations weaken the tooth structure. Amalgam needs complete removal and reinsertion on failure; repair is not advisable. It still faces controversy over mercury release and health hazards and environmental hazards associated with it. Amalgam is contraindicated in esthetic regions and pregnancy.

Advantages of composite resin: Biggest advantage of composite is its Esthetic appearance. Universal acceptance in esthetic zones makes composite indispensable. Relatively less complex tooth preparation conserves tooth structure leaving stronger remaining tooth structure to support restoration. Micromechanical bond with tooth structure results in good retention, low microleakage minimal interfacial staining. It has insulative effect and can be repaired.

Disadvantages of composite resin: Polymerization shrinkage takes a toll on clinical success of composites. Highly technique sensitive and need good isolation in order to form adequate bond with tooth structure. Insertion technique is more difficult, time consuming for dentist as multiple steps like etching, bonding and segmental insertion, curing and finishing and polishing are performed. Establishing proximal and occlusal axial contacts may be difficult. May exhibit greater occlusal wear, and is less Longitivity if used without bonding or self-etched.

CONCLUSION: Dental restorative materials have to fulfill several of requirements. Search for ideal material is still going on; different existing materials are still in a stage of development. Based on ease of handling, functionality, safety esthetics and cost effectiveness it is concluded that neither a universally applicable nor an ideal material is available for restorative dentistry ${ }^{40}$. However dental 
amalgam has served excellent for centuries and is a versatile restorative material, despite facing controversy over mercury toxicity 22,29,39. The use of amalgam has been decreasing in recent past, not as much because of public perception on mercury toxicity or environmental issues but due to the increased demand for esthetic restoratives ${ }^{41}$.Amalgam is superior over composite as it fulfills almost all criterions except esthetics. Amalgam is probably more durable than composite resins, especially used to large restore large cavities and cusp capping3,24-26,42-44. Unique self-margin sealing effect results in long term clinical success 3,30,38. The new high copper single composition alloys demonstrate superior mechanical properties 10,12,17-19,33,34 , but may not offer as good marginal seal as older amalgams. However amalgam is here to stay because it is more affordable ${ }^{1}$ for the patient and less technique sensitivity makes placement easy for the dentist ${ }^{25,29}$.

Composite resins are indispensable in anterior esthetic zones but also are viable alternative to amalgam for posterior restorations as well 1 . Though they are more technique sensitive 25 , but offer a better seal and meet the patient's demands for esthetics. Recent studies suggest doubts about their longevity are irrational and they perform well in clinical conditions. Their use in large restorations and in cusp capping situations is still a matter of debate $22,23,25$. Thus onus is on the dentist, to select right restorative material according to esthetic demand of patient and dynamics of the present lesion.

\section{REFERENCES:}

1. Heintze SD, Rousson V. Effectiveness of direct class II restorations. 2012; 14:407-31.

2. DENTAL DISEASE AND ORAL HEALTH. http://www.who.int/oral_health/publications/en/orh_fact_sheet.

3. B L Chadwick, P M H Dummer, F D Dunstan, A S M Gilmour, R J Jones, C J Phillips, J Rees, S Richmond, J Stevens, E T Treasure. What type of filling? Best practice in dental Restorations.1999; 8:202-7.

4. Akerboom HB, Advokaat JG, Van Amerongen WE, et al. Long-term evaluation of amalgam restorations. Comm Dent \& Oral Epidemiol 199; 21:45-8.

5. Capel CPE, Gomes MWJ, Ferreira SJF. Low-silver amalgam restorations: a two-year clinical evaluation. Dent Materials 1989; 5:277-80.

6. Gruythuysen RJ, Kreulen CM, Tobi H, et al. 15-year evaluation of Class II amalgam restorations. Comm Dent \& Oral Epidemiol 1996; 24:207-10.

7. Hamilton JC, Moffa JP, Ellison JA, et al. Marginal fracture not a predictor of longevity for two dental amalgam alloys: a ten-year study. J Prosthet Dent 1983; 50:200-2.

8. Jokstad A, Mjör IA. Analyses of long-term clinical behavior of class-II amalgam . Acta Odotol Scand 1991; 49:47-63.

9. Letzel H, van't Hof M, Vrijhoef M. The influence of the condensation instrument on the clinical behavior of amalgam restorations. J Oral Rehabil 1987; 14:133-8.

10. Mjör IA, Dahl JE, Moorhead JE. Age of restorations at replacement in permanent teeth in general dental practice. Acta Odontol scand 2000; 58:97-101.

11. Lundin SA, Andersson B, Koch G, et al. Class II composite resin restorations: a three-year clinical study of six different posterior composites. Swed Dent J 1990; 14:105-14.

12. Norman RD, Wilson NH. Three-year findings of a multiclinical trial for a posterior composite. J Prosthet Dent 1998; 59:577-83. 
13. Roulet JF. Benefits and disadvantages of tooth-coloured alternatives to amalgam. J dent 1997; 25:459-73.

14. Eriksen HM. A clinical evaluation of silicate and composite restorations after 3 years of use. J Oral Rehabil. 1974; 1:317-21.

15. Fukushima M, Setcos JC, Phillips RW. Marginal fracture of posterior composite resins. J Am Dent Assoc 1988; 17:577-83.

16. Grogono AL, McInnes PM, Zinck JH, et al. Posterior composite and glass ionomer/composite laminate restorations: 2-year clinical results. Am J Dent 1990; 3:147-52.

17. Hoyer I, Gangler P, Niemela S. Composite and amalgam fillings in a 4-year clinical comparison. Zahn-, Mund-, und Kieferheilkunde Mit Zentralblatt 1988; 76:721-6.

18. Wilder AD, Bayne SC, May KN, et al. Five-year clinical study of u.v.-polymerized posterior composites. J Dent 1991; 19:214-20.

19. American Dental Association (ADA) Council on Scientific Affairs. Statement on dental amalgam 2011.

20. George GN, Singh SP, Hoover J, Pickering IJ. The chemical forms of mercury in aged and fresh dental amalgam surfaces. Chemical Research in Toxicology 2009; 22:1761-4.

21. Kopperud SE, Tveit AB, Gaarden T, Sandvik L, Espelid I. Longevity of posterior dental restorations and reasons for failure. Eur J Oral Sci 2012; 120:539-48.

22. Anusavice KJ. Phillips' Science of Dental Materials. 11th edition. Philadelphia, Pa, USA: Saunders.

23. Paulette Spencer, Qiang Ye, Jonggu Park, Elizabeth M. Topp, Anil Misra, Orestes Marangos, Yong Wang, Brenda S. Bohaty, Viraj Singh, Fabio Sene, John Eslick, Kyle Camarda and J. Lawrence Katz. Adhesive/Dentin Interface: The Weak Link in the Composite Restorations. Published online 2010 February 27.

24. Demarco FF, Corrêa MB, Cenci MS, Moraes RR, Opdam NJ. Longevity of posterior composite restorations: not only a matter of materials. Dent Mater 2012; 28:87-101.

25. Sturdevant`s operative dentistry, Art and science of operative dentistry: Fourth Edition .Mosby, Missouri.

26. Collins CJ, Bryant RW, Hodge KLV.A clinical evaluation of posterior composite resin restorations: 8-year findings. J Dent 1998; 26:311-17.

27. Mari LH. Ten-year clinical assessment of three posterior resin composites and two amalgams. Quintessence Int 1998; 29:483-90.

28. Swartz ML, Phillips RW. In vitro studies on the marginal leakage of restorative materials. Journal of the American Dental Association 1961; 62:141-51.

29. Yurdanur Uçar and William A. Brantley. Biocompatibility of Dental Amalgams . International Journal of Dentistry 2011; article ID 981595: 7.

30. Zhang Zhanga, Yang Guo Biaoa. Measurement of polymerization shrinkage of composite resins with ESPI.2008; SPIE Digital library; Vol. 7155, 71552.

31. Braga RR,Ballester RY, Ferracane JL. Factors involved in the development of polymerization shrinkage stress in resin-composites: a systematic review. Dent Master 2005; 21:56-67.

32. Kleverlaan CJ, Feilzer AJ. Polymerization shrinkage and contraction stress of dental resin composites. Dent Master 2005; 21:962-70.

33. Dennison JP. Effect of variable light intensity on composite shrinkage. J Prosthet Dent 2000; 
84:499-505.

34. John R. condon , B. S,Jack L. Ferracane. Assessing the Effect of Composite Formulation on Polymerization Stress. Am Dent Assoc 2000; 131(4):497-503.

35. Karl F. Leinfelder. Is It Possible To Control The Directional Shrinkage Of Resin-Based Composites? J Am Dent Assoc 2001; 132: 782-3.

36. Giachetti L, Scaminaci Russo D, Bambi C, Grandini R. A review of polymerization shrinkage stress: current techniques for posterior direct resin restorations. Contemp J Dent Pract. 2006; 7:79-88.

37. Simecek JW, Diefenderfer KE, Cohen ME. An evaluation of replacement rates for posterior resin-based composite and amalgam restorations in U.S. Navy and Marine Corps recruits. J Am Dent Assoc 2009; 140:200-9.

38. American Dental Association (ADA) Council on Scientific Affairs. Dental amalgam: update on safety concerns. The Journal of the American Dental Association 1998; 129:494-503.

39. Anusavice KJ. Phillips' Science of Dental Materials. 10th edition. Philadelphia, Pennsylvania, USA: Saunders.

40. Ned Tijdschr Tandheelkd. The ideal restorative material. PMID: 11921984. 1996; 103:435-6.

41. Ramesh Bharti, Kulvinder Kaur Wadhwani, Aseem Prakash Tikku, and Anil Chandra. Dental amalgam: An update. J Conserv Dent 2010; 13: 204-208.

42. Ramesh Bharti, Kulvinder Kaur Wadhwani, Aseem Prakash Tikku, Anil Chandra. Dental amalgam: An update. J Conserv Dent 2010; 13:204-8.

43. Simecek JW, Diefenderfer KE, Cohen ME. An evaluation of replacement rates for posterior resin-based composite and amalgam restorations in U.S. Navy and Marine Corps recruits. J Am Dent Assoc 2009; 140:200-9.

44. A. Shenoy. Is it the end of the road for dental amalgam? A critical review. J Conserv Dent 2008; 11(3):99-107.

\section{AUTHORS:}

1. Bhagyashree Patki

\section{PARTICULARS OF CONTRIBUTORS:}

1. Dental Surgeon, Department of Prosthodontics, Keep Smiling Dental Clinic, Mumbai.

\section{NAME ADDRESS EMAIL ID OF THE CORRESPONDING AUTHOR:}

Dr. Bhagyashree Patki, Shop No. 5, Haji Kasam Bldg, Dilima Street, Dockyard Road, Mumbai - 10. Email - bhagyashreepatki@gmail.com

Date of Submission: 30/10/2013. Date of Peer Review: 31/10/2013. Date of Acceptance: 07/11/2013. Date of Publishing: 12/11/2013 